\title{
SOCIEDADE POLICONTEXTURAL, SENTIDO JURÍDICO E EFETIVIDADE
}

\author{
Paulo Roberto Ramos Alves ${ }^{1}$
}

\section{Resumo}

A sociedade contemporânea é permanentemente construída a partir de uma paradoxal tentativa de redução de sua complexidade. Tais operações são construídas no âmbito interno de sistemas organizacionais que, em razão de sua capacidade decisória, permitem que a complexidade seja trabalhada. Uma dessas organizações é o Poder Judiciário. Nesse contexto o sistema do direito é constituído a partir de um conjunto de operações decisórias que, obrigatoriamente, coexistem com outras racionalidades sistêmicas, produzindo uma crise (interna e externa) de efetividade das decisões judiciais. Logo, fazem-se necessárias observações diferenciadas a fim de serem construídas alternativas para tal problema.

Palavras-chave: Direito; Efetividade; Poder Judiciário; Policontexturalidade; Teoria dos Sistemas.

\section{INTRODUÇÃO}

O direito afirma-se como um sistema comunicativo capaz de delimitar seus próprios pressupostos operativos. Nesse contexto, a realidade aposta pelo discurso jurídico igualmente coexiste com outras racionalidades sistêmicas, como a política ou a religião, caracterizando uma incrível pluralidade de discursos sociais existentes no âmbito do sistema comunicativo global entendido como sociedade. A A sociedade contemporânea é denominada como funcionalmente diferenciada ${ }^{2}$ justamente em razão de sua capacidade de evolução, o que se dá mediante a construção de pontos de observação específicos, cuja capacidade de atribuição de sentido a comunicações socialmente difusas evidencia-se diante do surgimento de sistemas funcionais dotados de função e codificação próprias.

Muito embora essa racionalidade plural manifeste-se no âmbito da sociedade, evidenciando a existência de diversos sistemas de atribuição de sentido, o mesmo ocorre no âmbito de outros sistemas funcionais, como o

\footnotetext{
${ }^{1}$ Doutor em Direito pela Universidade do Vale do Rio dos Sinos e graduado em Direito pela Universidade de Passo Fundo (2007). Professor na Universidade de Passo Fundo e na Universidade do Oeste de Santa Catarina. E-mail: pauloalvess@yahoo.com.br

${ }^{2}$ Vale salientar que se evita propositalmente designar a sociedade contemporânea como pós-moderna, eis que tal conceito é alvo de frequentes mal-entendidos, inexistindo um consenso sobre tal definição, o que, via de regra, deságua em debates infrutíferos, colaborando para o distanciamento da discussão proposta. Por tais razões, opta-se pela caracterização do atual momento sob a denominação sociedade contemporânea ou sociedade diferenciada funcionalmente, sendo ambas expressões utilizadas nas linhas que seguem.
} 
Direito. Ao mesmo tempo em que se fala em pluralidade e diferenças no meio social, esse fenômeno passa a ser observado no âmbito jurídico, evidenciando que a racionalidade do sistema do direito não depende única e exclusivamente da centralidade estatal. Por outro lado, o direito reclama efetividade. O problema central do Poder Judiciário atualmente é justamente a falta de efetividade em suas decisões. Como, porém, equalizar o problema da efetividade com o reconhecimento da policontexturalidade da sociedade funcionalmente diferenciada?

O problema que se apresenta diz respeito justamente às formas de assimilação de tais diferenças no âmbito do direito. Conforme será observado nas páginas que seguem, o Direito - assim como os demais sistemas sociais - não é capaz de produzir comunicações diretamente, dependendo de instituições que possuem a capacidade decisória e, por isso, a capacidade de produzir comunicações. O Poder Judiciário é uma dessas instituições que se identificam na forma de sistemas organizacionais.

O reconhecimento da policontexturalidade da sociedade (e do direito) oferece um campo vastíssimo para a observação de novos rumos para a prática jurídica. Nesse passo, após demarcada forma pela qual a sociedade opera, bem como observada a realidade policontextural que igualmente caracteriza a sociedade funcionalmente diferenciada, a segunda parte do presente trabalho ocupar-se-á com a construção da realidade social pela atuação dos sistemas organizacionais - em particular o Poder Judiciário -, bem como pela produção do sentido jurídico pela prática dos tribunais.

A dupla questão da policontexturalidade e efetividade, contudo, apresenta-se como o plano de fundo de todo o trabalho. A discussão sobre a produção do sentido jurídico em um contexto policontextural é a linha mestra das linhas que seguem, mantendo-se como problema, justamente, a necessidade de formas de observação diferenciadas pelos tribunais diante de uma realidade difusa e plural.

\section{SOBRE A AUTODESCRIÇÃO POLICONTEXTURAL DA SOCIEDADE CONTEMPORÂNEA}

A sociedade contemporânea se autodescreve como funcionalmente diferenciada. Isso significa que, quando se fala em sociedade, se fala igualmente em comunicações e no desempenho de funções por atores sistêmicos cuja racionalidade específica permite a atribuição de sentidos próprios para as comunicações socialmente produzidas. Parte-se, portanto, do reconhecimento de que a existência de sistemas é uma realidade presente na sociedade atual.

Nesse contexto, afirmam-se inúmeras racionalidades concorrentes, possibilitando pontos de observação distintos e, por vezes, contraditórios. Pense-se, por exemplo, no interminável conflito entre a racionalidade econômica e a jurídica: ao observar a realidade desde sua distinção constitutiva (ganho/perda), a relevância atribuída por seu código fundamental não permite que a economia se ocupe com critérios legais que, por sua vez, 
fundam-se na distinção própria do sistema jurídico.

Essa realidade permeia todos os sistemas funcionais da sociedade autoproclamada funcionalmente diferenciada, trazendo incontáveis consequências para a observação da prática jurídica cotidiana. Uma dessas consequências é justamente o reconhecimento do que se denomina policontexturalidade e seus reflexos na forma pela qual o direito comumente opera por intermédio de sua principal organização: o Poder Judiciário.

A parte posterior do texto se ocupará da análise das organizações identificadas como tribunais, e, no momento, serão observados alguns pressupostos sistêmicos sob os quais a sociedade funcionalmente diferenciada tem sua operacionalidade, iniciando-se com a observação de elementos como a complexidade, diferenciação e comunicação. Em seguida, o discurso se atém à realidade policontextural na qual essa mesma sociedade e o direito são inseridos, proporcionando o instrumental teórico para as posteriores observações sobre as decisões organizacionais e o papel dos tribunais na atribuição do sentido jurídico às comunicações.

\section{OBSERVAÇÕES SOBRE A OPERACIONALIDADE SISTÊMICA NA SOCIEDADE FUNCIONALMENTE DIFERENCIADA}

Ao autodescrever-se como funcionalmente diferenciada, a sociedade contemporânea assume a evidente necessidade do autodesenvolvimento de complexidade. Ao caracterizar-se como o sistema social que engloba todas as comunicações (LUHMANN, 1997, p. 80), a sociedade produz um excedente de possibilidades para essa mesma comunicação. Logo, a própria comunicação é condição para a existência de comunicações posteriores (LUHMANN, 2007, p. 48). O sucesso das comunicações, contudo, pressupõe que sempre existem mais possibilidades do que aquelas que se pode realizar em um dado momento, razão pela qual se passa a falar em complexidade.

A complexidade pode ser observada como um excedente de possibilidades socialmente produzido, sendo que esse excesso de alternativas constrange essa mesma sociedade à formação de sistemas funcionais de modo a assegurar o tratamento dessa complexidade. Luhmann (2007, p.101) afirma que um sistema complexo é aquele que não se mostra totalmente ordenado nem totalmente desordenado. Isso evidencia que os sistemas sociais funcionam, paradoxalmente, com base na unidade da diferença entre ordem/desordem, estabilidade/instabilidade, ou, ainda, com base na distinção complexidade organizada/complexidade desorganizada.

A noção de complexidade aponta para o reconhecimento de que existe uma grande quantidade de possibilidades, sendo que essas alternativas não são realizáveis ao mesmo tempo. Coexistem inúmeras alternativas concorrentes, pois, ao decidir algo, as demais alternativas ainda permanecem como escolhas possíveis. Ao se indicar algo, necessariamente outras possibilidades serão excluídas da decisão, ainda que permaneçam como 
alternativas. A complexidade é caracterizada justamente como esse excesso de possibilidades socialmente produzido, razão pela qual se torna possível observar a sociedade como a unidade da multiplicidade.

Por sua vez, essa "totalidade das possibilidades de experiências ou ações, cuja ativação permita o estabelecimento de uma relação de sentido" (LUHMANN, 1983, p. 12), atua como o medium que possibilita a igual observação da sociedade como contingente, isto é, partindo-se do fato de que "as possibilidades apontadas para as demais experiências poderiam ser diferentes das esperadas" (LUHMANN, 1983, p. 12) frente à tomada de decisões, evidencia-se a possibilidade de frustrações diante de determinada alternativa selecionada.

Todo esse excedente de possibilidades passa a requerer operações para a viabilização de seu enfrentamento, com a consequente construção da realidade social pela seleção de alternativas entre as várias possíveis. A realidade social, desse modo, relaciona-se permanentemente com processos decisórios, sendo que tais processos são viabilizados no âmbito sistêmico-organizacional. Em outras palavras, a sociedade exige mecanismos capazes de assimilar a hipercomplexidade ambiental mediante a complexificação de mecanismos capazes de decidir (ROCHA, 2008, p. 169-170).

É nessa realidade que se afirma a existência de sistemas sociais. Os sistemas atuam como mediadores "entre a extrema complexidade do mundo e a pequena capacidade do homem em assimilar as múltiplas formas de vivência" (NEVES, 1997, p. 12), complexificando-se internamente para reduzir a complexidade do entorno, demonstrando, com isso, sua maior ou menor capacidade racional, o que é evidenciado de acordo com suas possibilidades comunicativas de controlar seus ambientes por meio do controle de si próprios (ROCHA, 1994, p, 12). Por isso, quando se fala em complexidade e sistema, se observa o sistema como complexidade organizada.

Diante desta enorme complexidade comunicativamente autoproduzida, a sociedade contemporânea desenvolve mecanismos capazes de transformar essa complexidade desorganizada em complexidade organizada, ou seja, em produtos específicos da comunicação cujo sentido passa a ser possibilitado pela atuação de racionalidades sistêmicas específicas. Dito de outro modo, desenvolvem-se sistemas sociais capazes de abarcar a complexidade social, estabilizando essa complexidade internamente. Paradoxalmente, essa estabilização sistêmica da complexidade social acaba por gerar complexidade funcionalmente produzida, sendo que, quanto maior a complexidade intrasistêmica maior a capacidade de controle do próprio entorno.

O direito é justamente um desses sistemas sociais. O sistema jurídico estrutura respostas para a problemática da verdade de acordo com seus próprios pressupostos operacionais, estabelecendo a duração temporal das operações jurídicas e as estabilizando socialmente (ROCHA, 2008, p. 169-170). Todo e qualquer acontecimento jurídico apenas adquire relevância no interior do próprio sistema do direito. As observações realizáveis pelo direito apenas podem ser realizadas pelo direito, tornando-se acessíveis aos demais sistemas sociais (como a economia ou a política, por exemplo), tão somente por meio de perturbações ou ressonâncias 
(LUHMANN, 1989, p.15-16), não havendo a possibilidade de que as comunicações juridicamente produzidas delimitem diretamente a realidade de outros discursos sociais.

O Direito opera sob a forma particular direito/não-direito, apresentando-se como um dos subsistemas sociais cuja ativação dá-se precisamente em razão do desenvolvimento da sociedade como um todo, adquirindo sua autonomia funcional em decorrência dos problemas reiteradamente produzidos no curso da história da sociedade, bem como da consequente necessidade de sua regulação (LUHMANN; DE GIORGI, 1993, p. 327). Nesse contexto, a evolução do direito não implica em progresso ou em eventuais melhorias. A evolução, portanto, relaciona-se com os processos de diferenciação por meio dos quais o sistema adapta-se à realidade do momento, tornando-se capaz de produzir respostas de acordo com a binariedade específica que o caracteriza. ${ }^{3}$

Os sistemas, enquanto aquisição evolutiva da sociedade, operam de forma binária. Aceitando um código binário (direito/não-direito), o sistema jurídico é (auto)obrigado a essa bifurcação, passando a reconhecer como operações próprias somente aquelas que se relacionam com essa binariedade (LUHMANN, 1994, p. 18). A partir desse momento, somente pode-se falar em comunicações jurídicas quando determinada comunicação manter relação com essa codificação específica do sistema do direito.

Quando se fala em diferenciação funcional, portanto, está se falando no reconhecimento do desempenho de funções específicas por sistemas específicos. Diante dessa realidade, os conflitos são internalizados sistemicamente, sendo substituídos por comunicações específicas. No caso do sistema jurídico, as comunicações podem assumir tão somente a forma jurídica, não sendo possível, por exemplo, buscar explicações econômicas ou políticas para a realidade jurídica. Logo, com base nesse reconhecimento, rompe-se com a possibilidade de uma verdade unívoca ou com a busca por um fundamento último ${ }^{4}$ para o direito ou para a

\footnotetext{
3 Todo o movimento da sociedade, por sua vez, evolui mediante o estabelecimento de um certo sentido particular para as comunicações. A recursividade de determinadas comunicações, como a jurídica, econômica, religiosa ou política, promove, via de consequência, a evolução sistêmica por meio de processos de diferenciação funcional. A evolução social relaciona-se com a especificação de funções particulares por determinados sistemas. Para maiores detalhes vide LUHMANN, La sociedad de la sociedad, p. 393

${ }^{4}$ Luhmann explica a impossibilidade de observar a própria condição para a observação de algo. Em outras palavras, não é possível ver que não se vê aquilo que não se vê. $O$ direito não pode ser operacionalizado juridicamente, sob pena no bloqueio no processo decisório. Por sua vez, Teubner igualmente denuncia esse problema no momento em que demonstra a ocorrência dos chamados paradoxos da autorreferência, sendo tais paradoxos o resultado da irresistível busca por $m$ fundamento último para o direito, aplicando-se a distinção constitutiva (direito/não-direito) a si própria. Essa auto-aplicação do próprio código jurídico inegavelmente conduziria à conclusões sobre a impossibilidade jurídica de aplicação do próprio código jurídico. Sobre tal aspecto vide LUHMANN, Niklas. A terceira questão: o uso criativo dos paradoxos no Direito e na história do Direito. Estudos jurídicas, São Leopoldo, n. 32 , jan./jun., 2006. p. 46. LUHMANN, Niklas. ¿Cómo se pueden observar estructuras latentes? In: WATZLAWICK, Paul; KRIEG, Peter. El ojo del observador: contribuciones al constructivismo. Barcelona: Gedisa, 1998. p. 63. TEUBNER, Gunther. O direito como sistema autopoiético. Lisboa: Fundação Calouste Gulbenkian, 1989. p. 6-10. MAGALHÃES, Juliana Neuenschwander. O uso criativo dos paradoxos do direito. In: ROCHA, Leonel Severo. Paradoxos da auto-observação: percursos da teoria jurídica contemporânea. Curitiba: JM, 1997. p. 248-249. ROCHA, Leonel Severo. Observações sobre a observação luhmanniana. In ROCHA, Leonel Severo, KING, Michael; SCHWARTZ, Germano. A verdade sobre a autopoiese no direito. Porto Alegre: Livraria do Advogado, 2009. p. 21-23.
} 
sociedade, sendo que os diversos discursos sociais também operam mediante códigos próprios, possibilitando a igual criação de realidades baseadas no sentido atribuído pela particularidade de seus códigos.

Todas essas considerações introdutórias são de elementar relevância para a observação do direito como sistema autopoiético. A ideia de autopoiese pressupõe, paradoxalmente, a abertura pelo fechamento, o contínuo diálogo entre repetição e estabilidade e a permanente reconstrução do tempo com base na distinção passado/futuro. ${ }^{5}$ Essas operações permitem que o direito construa sua realidade e afirme-se como unidade e, enquanto unidade, objetive operações específicas para o tratamento de sua própria complexidade.

Ao mesmo tempo em que se desenvolvem complexas unidades capazes de atribuir sentidos próprios para comunicações difusas, o direito passa a enfrentar nítidos problemas relacionados à sua efetividade. Quando a observação da realidade é deslocada de uma perspectiva unitária para a perspectiva da policontexturalidade, não existem outros caminhos senão o repensar da forma pela qual as organizações do sistema do direito atribuem o sentido jurídico da realidade.

\section{DA UNIDADE A MULTIPLICIDADE: SISTEMA, POLICONTEXTURALIDADE E EFETIVIDADE}

Ao mesmo tempo em que uma grande quantidade de discursos sociais se autonomiza, especificando-se funcionalmente diante do sistema social geral, a sociedade passa a observar-se como sociedade policontextural. A policontexturalidade espelha a possibilidade de coexistência de diversas racionalidade sistêmicas concorrentes, não atribuindo primazia a nenhuma delas. Isso importa no reconhecimento de que coexistem inúmeros pontos de observação concomitantes, sendo a observação jurídica uma dessas observações possíveis.

Vale dizer que a noção de policontexturalidade caracteriza-se intrinsecamente pela possibilidade de observações diferenciadas. Nesse aspecto, Luhmann aduz que "un sistema [...] puede observarse a sí mismo simultánea o sucesivamente de maneras muy diversas - diríamos que policontexturales" (LUHMANN, 2007, p. 62). Logo, é possível observar a policontexturalidade sob um duplo aspecto, sendo que, primeiro, designa a nítida fragmentação dos discursos sociais e, em segundo lugar, espelha a própria reflexividade do direito, eis que essa fragmentação passa a ser igualmente tematizada pelo sistema jurídico, assumindo a forma de problemas jurídicos.

O problema torna-se mais vultoso quando se observa que aquela característica designada pela sociedade

\footnotetext{
${ }^{5}$ A simultaneidade do tempo é um fator presente nos debates jurídicos. Sobre tal aspecto LUHMANN, Niklas. El derecho de la sociedad. Ciudad de México: Universidad Iberoamericana/Herder Editorial, 2005. p. 101 afirma que "si el punto de partida de la reflexión lo constituyen las operaciones autoproducidas, entonces se sigue que todo lo que sucede, acontece en el presente. Esto significa también: todo lo que acontece, sucede de manera simultánea. Tanto el pasado como el futuro son contemporáneos y relevantes sólo en la simultaneidad. Pasado y futuro son horizontes de tiempo de cada una de las operaciones y pueden tan sólo como tales ser distinguidos en el presente".
} 
contemporânea como policontextural é reproduzida no âmbito interno do sistema jurídico. Teubner (2005, p.85) denuncia o problema do "dilema perturbador da autopoiese na autopoiese, que se coloca para campos sociais autônomos". Isso significa que, ao mesmo tempo em que a sociedade é policontextural (ou plural, multicultural), o próprio sistema jurídico reconstrói essa pluralidade internamente a partir do que se pode chamar de policontexturalidade jurídica.

A perspectiva da policontexturalidade é assumida por Teubner sob uma perspectiva diversa daquela de Luhmann. Teubner aloca a ideia de policontexturalidade no âmbito do próprio sistema jurídico, enquanto Luhmann reconhece que apenas a sociedade é policontextural. Nesse passo, a perspectiva de Teubner insere a ideia de uma pluralidade de verdades possíveis igualmente no âmbito jurídico (ROCHA, 2008, p. 22-23), fazendo com que a própria ideia de direito assuma um viés policontextural.

Por isso, a policontexturalidade pode ser vista na forma de uma proposta teórica capaz de viabilizar a observação dos novos sentidos construídos pela teoria jurídica. Essa noção, então, afirma-se sob dois aspectos: em primeiro lugar evidencia-se o fato de que o direito mantém contato com diversos discursos sociais (como a política, economia, religião, educação, ciência, etc), sem que, contudo, tais discursos determinem os rumos jurídicos. Já, em segundo lugar, evidencia-se o reconhecimento de que o próprio código jurídico (direito/nãodireito) comporta discursos paralelos àqueles centrados na figura do Estado. Em outras palavras, o direito não se vincula apenas à centralidade estatal, amoldando-se de forma igualmente plural no âmbito interno do sistema jurídico.

Nota-se, portanto, que o sistema jurídico possui a capacidade de observar a emergência de novos direitos (autônomos e periféricos) que emergem da complexa teia das relações comunicativas sociais (ROCHA, 2009, p. 39). Logo, para além do direito estatal, a sociedade produz pulsantes discursos jurídicos, que surgem no âmbito de organizações difusas e que não guardam qualquer dependência para com a centralidade do Estado. Nesse contexto, o que é observado sob a noção de pluralismo jurídico ou policontexturalidade pode, igualmente, ser visto como a unidade de discursos sociais fragmentários e autônomos que observam a realidade mediante o sentido atribuído pela distinção direito/não-direito (CARVALHO, 2008, p. 22).

Neves salienta que a diferença entre sistema e ambiente passa a ser desenvolvida em diversos âmbitos da comunicação, afirmando-se distintas formas sistêmicas autônomas. Por outro lado, o autor salienta que a policontexturalidade implica em múltiplas autodescrições da sociedade, o que vai ao encontro da mencionada formação de racionalidades parciais conflitantes. A sociedade contemporânea, portanto, não possui nenhuma hierarquização ou verticalidade, não sendo organizada desde uma perspectiva de um centro único de poder, mas sim a partir do reconhecimento da policontexturalidade (NEVES, 2009, p. 23-24).

Dito de outro modo, na sociedade contemporânea tornou-se possível a observação da existência de 
manifestações jurídicas que não mais emanam do Estado, mas que se vinculam igualmente à distinção direito/não-direito. Essas manifestações são identificadas, por exemplo, na regulação de corporações privadas transnacionais, na regulação criada pelos próprios detentos no interior de presídios, na normatividade emanada de coletividades, nos estatutos de sindicatos e ONGs, e assim por diante.

Logo, o discurso jurídico contemporâneo passa a reclamar por efetividade. A discussão sobre a efetividade do direito toma o lugar então ocupado por discussões sobre sua validade. Quando se parte de uma observação sistêmica, não mais cabe discutir sobre a validade do direito, afinal, se há direito, esse direito é válido. A validade, em linhas gerais, aponta para a aceitação da comunicação jurídica pela própria comunicação jurídica, ou seja, é um símbolo próprio do sistema do Direito. Isso significa que tal símbolo não pode ser utilizado em nenhum outro lugar da sociedade. Para Luhmann (2005, p. 158-159), todo o direito é direito válido e vigente. Não é possível falar em direito sem validade e vigência.

O problema relacionado ao símbolo da validade, por sua vez, diz respeito à própria identificação do reconhecimento da validade, eis que este símbolo não pode ser identificado como uma regra entre as regras vigentes. A validade, portanto, assume a forma pela qual as operações jurídicas referem-se à sua própria operacionalidade no interior do sistema. Logo, a validade é afirmada pelo próprio movimento do direito. Apresentando-se como um produto do sistema jurídico, ela se afirma constantemente mediante a integração das operações jurídicas na própria rede das operações jurídicas (LUHMAN, 2005, p. 158-159).

De forma resumida, portanto, a validade refere-se à própria possibilidade das operações do direito, ou seja, a contínua modificação do estado de validade do sistema é o que permite se falar em direito válido ou não. A validade, dessa maneira, diz respeito à própria autopoiese do sistema, escapando de qualquer possibilidade de vinculação à metanormas, como uma eventual norma fundamental (Kelsen) ou uma regra de reconhecimento primária capaz de oferecer validade às normas secundárias (Hart).

A partir do reconhecimento de que não há direito que não seja válido a discussão é transposta para outro nível, relacionando-se com a prática jurídica, então, o problema da efetividade das operações do sistema do direito. Rocha afirma que o problema do direito nas sociedades complexas é justamente a questão da efetividade nos processos de tomada de decisão, sendo que o Poder Judiciário ocupa a função primordial de operacionalizar efetivamente o discurso jurídico com a realidade social (ROCHA, 2009, p. 32-33).

Quando se fala em efetividade regulativa, está pressuposto que o discurso se refere ao reconhecimento da evidente coevolução entre racionalidades jurídicas diversas e, por vezes, conflitantes (CARVALHO, 2008, p. 22). Essa realidade é reconhecida por Teubner no momento em que observa que há uma tendência à expansão do sistema jurídico a partir de sua periferia, e não mais a partir de centros politicamente delimitados ou estatalmente vinculados (TEUBNER, 1997, p. 4). 
Teubner radicaliza a - já radical - proposta luhmanniana quando conduz a noção de policontexturalidade para o âmbito interno do sistema jurídico. Enquanto Luhmann não aceita o pluralismo jurídico diante do reconhecimento quanto à existência de uma sociedade global, Teubner (2005, p. 85) indaga se a interdiscursividade no direito e na sociedade não seria muito mais densa do que permite a observação dos conceitos de perturbação e ressonância aos quais se submetem sistemas funcionais autônomos.

A partir dessa indagação, Teubner delimita três aspectos questionando a ideia acoplamento estrutural entre sistemas autônomos. $\mathrm{O}$ primeiro aspecto refere-se à insuficiência do conceito de perturbação para a compreensão dos conceitos de abertura e fechamento dos sistemas funcionais. Em segundo lugar, observa o surgimento de instituições sociais que atuam como elementos de ligação entre racionalidades concorrentes. Por fim, traz à discussão o conceito de responsividade, delimitando que o pluralismo jurídico se afigura como um direito voltado à sociedade justamente por aproveitar o diálogo entre a as operações jurídicas e sociais e, com isso, complexificando o sistema jurídico de acordo com essa pluralidade (TEUBNER, 2005, p. 85).

Nesse passo, ao se reconhecer o direito como policontextural, o problema da multiplicidade de discursos jurídicos é realocado no interior do próprio sistema do direito forçando que esse mesmo sistema - pela atuação de suas organizações - assimile e ordene tal complexidade. Em outras palavras, a solução para os conflitos entre ordens normativas ou a observância jurídica das diferenças não pode ser dado por autoridades econômicas ou políticas, por exemplo, cabendo unicamente ao direito sua reconstrução com base nessa pluralidade de vivências.

Como dito no início do capítulo, a sociedade contemporânea compõe-se comunicativamente. O sucesso das comunicações, contudo, depende da existência de mecanismos com capacidade decisória. Evidentemente, a sociedade depende de uma espécie de sistemas sociais que se identifica na forma de sistemas organizacionais para que a continuidade da comunicação seja possibilitada.

\section{ORGANIZAÇÃO E POLICONTEXTURALIDADE: SOBRE A ATUAÇÃO DOS TRIBUNAIS NA CONSTRUÇÃO DO SENTIDO JURÍDICO}

O discurso jurídico-sociológico contemporâneo encontra, na teoria dos sistemas sociais, um amplo campo de investigação de uma realidade reconhecidamente dependente de sistemas capazes de operar em níveis hipercomplexos. Logo, a própria forma como o Direito e o Estado são observados assume um viés comunicativo no âmbito de uma sociedade vista como funcionalmente diferenciada e, portanto, dependente de decisões.

A realidade jurídica contemporânea, por sua vez, depende enormemente da atuação dos tribunais para sua constante atualização e estabilização. Evidentemente quando se fala em estabilização não se afirma que a sociedade ou o direito possam construir critérios de estabilidade ou uma linearidade racionalmente controlável. Estabilização, no sentido sistêmico, pressupõe justamente a instabilidade. Luhmann já afirmava paradoxalmente 
que a sociedade (e, claro, o direito) apenas é estável na instabilidade (1993, p. 218-219).

Os tribunais, enquanto organizações do sistema jurídico, constroem a realidade jurídica por meio de decisões. Como será observado a seguir, a decisão é o elemento fundamental das organizações formais que se desenvolvem no âmbito dos sistemas funcionais. Os tribunais tornam possível a decisão jurídica, permitindo que o direito estabilize expectativas comportamentais. Por outro lado, o sentido jurídico atribuído pelo código direito/não-direito apenas pode ser possibilitado pela atuação do Poder Judiciário.

Para tanto, em um primeiro momento, serão observados alguns aspectos referentes à forma pela qual a sociedade possibilita o desenvolvimento de organizações formais, bem como o papel dessas organizações na construção da realidade social. Em seguida, considerando que os sistemas funcionais possuem uma limitação cognitiva fundada em uma distinção binária, busca-se observar os tribunais como o local privilegiado para a construção do sentido próprio do sistema jurídico.

\section{A CONSTRUÇÃO DA REALIDADE: ORGANIZAÇÃO E DECISÃO}

A sociedade é observada como o sistema omniabarcador de todas as comunicações. Quando se fala em sociedade, reconhece-se que o discurso pressupõe a tematização de comunicações. Entretanto, a sociedade diferenciada funcionalmente possui um problema, que é traduzido em sua dependência para com outra espécie de sistema social, os sistemas organizacionais.

A comunicação é um evento altamente improvável (LUHMAN, 2001, p. 41-44) ${ }^{6}$ e, ao mesmo tempo, a sociedade não é capaz de produzir comunicações. Tendo em vista a paradoxal incapacidade dos sistemas sociais em produzirem as comunicações que os caracterizam, esses mesmos sistemas possibilitam o desenvolvimento de instituições capazes de decidir e, assim, igualmente capazes de produzir comunicações. Essas instituições são identificadas como organizações formais. As organizações nada mais são do que uma espécie de sistema social que se caracterizam decisoriamente (LUHMANN, 2005, p.14), bem como se afirmam como dotados de capacidade de decidir em níveis hipercomplexos.

Evidentemente as organizações vinculam-se a determinados sistemas sociais, como os bancos à economia, as escolas à educação e os tribunais ao direito. A produção comunicativa no âmbito da sociedade vincula-se imediatamente às organizações formais (MARCH; SIMON, 1972, p.17). Logo, a racionalidade

\footnotetext{
${ }^{6}$ Para Luhmann a improbabilidade da comunicação se dá por três razões: a primeira, no sentido de que é muito pouco provável que alguém entenda o que o outro tem a dizer, eis que a compreensão do sentido da comunicação se dá em face de um contexto baseado na memória do receptor/interlocutor; a segunda improbabilidade diz respeito à extensão espacial e temporal, tendo em vista que dificilmente uma comunicação atingirá mais pessoas do que aquelas que se encontram em dada situação. Finalmente, a terceira improbabilidade refere-se à obtenção do resultado almejado, compreendido enquanto adoção da informação e a incorporação desta ao seu próprio comportamento.
} 
jurídica depende da operacionalidade organizacional dos tribunais como forma de produção do sentido específico do direito. No direito, os tribunais ocupam o centro do sistema, enquanto a legislação e outras manifestações jurídicas descentralizadas passam a ocupar sua periferia (LUHMANN, 1990, p. 160-163). A ideia de policontexturalidade é resgatada aqui como uma realidade a ser observada pela prática dos tribunais enquanto organizações do sistema jurídico.

Corsi (2001, p. 175-176) entende as organizações como "aquele tipo de sistema social que produz decisões e que, para fazê-lo, elabora seus próprios critérios, tais como: regras de pertinência, procedimentos, hierarquias, programas, etc". Essa realidade, em última análise, significa, conforme Luhmann, que os sistemas organizacionais tematizam decisões enquanto produtos de outras decisões, vinculando decisões mutuamente entre si (LUHMANN, 2005, p. 14).

Quando se fala em organizações, estão pressupostas determinadas características específicas. Em primeiro lugar, as organizações possuem uma origem racional, orientando sua operacionalidade teleologicamente. Em outras palavras, possuem uma finalidade específica a ser cumprida, ao contrário dos sistemas funcionais aos quais pertencem. Nesse sentido, pode-se afirmar que o direito não possui uma finalidade. Somente é possível falar em finalidade quando se fala dos tribunais. Enquanto o direito (latu sensu) ocupa-se com sua própria autopoiese, os tribunais são constrangidos à decisão. A finalidade dos tribunais é justamente a decisão (LUHMANN, 2005, p. 269).

Em segundo lugar, há uma nítida divisão de trabalho e uma necessária hierarquização de poder. Essa característica pode ser observada, no Poder Judiciário, pela divisão de funções e na hierarquia das decisões dos tribunais. Existem tribunais de primeiro e segundo graus, juízes, desembargadores, assessores, etc, o que assegura, conforme Luhmann, que os erros sejam mantidos dentro de um contexto minimamente aceitável pela própria organização (2005, p. 391-392). Os limites da decisão organizacional são dados pela própria organização.

Em terceiro lugar, as comunicações produzidas pelos tribunais direcionam-se a uma adequação para determinada finalidade, orientando-se a partir de relações de troca com seu meio circundante (NAFARRATE, 1998, p. 24-25). Essa vinculação é facilmente verificada na maneira pela qual os tribunais operam. Enquanto organizações, os tribunais orientam-se justamente com base nessa teleologia e, como mencionado, procedendo desde uma perspectiva hierárquica no que tange à distribuição de atribuições de seus membros.

Nesse aspecto, cabe notar que a organização identificada como Poder Judiciário conta com uma especificidade que não é verificada em nenhum outro sistema social: a decisão é obrigatória. A forma pela qual a complexidade estrutura-se não permite aos juízes e tribunais a alternativa da não decisão. ${ }^{7}$ É justamente a

\footnotetext{
${ }^{7}$ O que é observado no artigo 5, inciso XXXV da Constituição Federal de 1988. Observe-se, igualmente, a possibilidade (construtiva) de abertura do sistema jurídico pelo seu fechamento no artigo $4^{\circ}$ da Lei de Introdução às Normas de Direito
} 
proibição do non-liquet que avoca para o sistema a competência universal para todas as questões jurídicas, bem como assegura a liberdade do sistema na permanente reconstrução de sua realidade (LUHMANN, 1990, p. 160163).

Ademais, pode-se salientar uma quarta característica como a capacidade organizacional quanto à definição dos critérios a serem observados para o eventual ingresso de membros na organização. Dito de outro modo, a distinção membro/não-membro é realizada no âmbito da organização como forma de delimitação daquelas condições a serem observadas por aqueles que desejem participar dessa espécie de sistema (MANSÍLLA, 2004, p. 22).

Essa realidade implica na observação de que os sistemas organizacionais se diferenciam no interior dos sistemas funcionais em razão de sua capacidade decisória (CORSI, 2001, p. 175-176). As organizações produzem decisões e são, ao mesmo tempo, produzidas decisoriamente. A decisão é o elemento fundamental de qualquer sistema organizacional. Por isso, as organizações produzem múltiplas possibilidades de decisões, bem como disponibilizam decisões como produto de outras decisões (LUHMANN, 2007, p. 658-659).

As organizações reconstroem o próprio tempo em seu interior. Pense-se novamente nos tribunais. Os tribunais são uma espécie de sistema social que produz decisões a partir do centro do sistema jurídico (LUHMANN, 1990, p. 160-163), vinculando todas as operações posteriores do sistema. As decisões dos tribunais orientam-se a partir de decisões passadas. A jurisprudência nada mais é que o resultado de decisões anteriormente tomadas que servem como premissa decisória para novos casos. Por outro lado, essa mesma capacidade decisória interfere no modus operandi dos próprios procedimentos internos da organização.

A afirmação de que as organizações reconstroem o tempo, por assim dizer, refere-se, portanto, à própria forma decisória pela qual esses sistemas são constituídos. Sistemas organizacionais mantêm uma intrínseca dependência entre processos seletivos passados, presentes e futuros (LUHMANN, 2005, p. 14). Nesse passo, a complexidade é constituída na forma de uma relação permanente entre decisões. A possibilidade da decisão de certa maneira une o passado/futuro, revestindo-se como a unidade entre o que já se decidiu (passado) e o que se decidirá (futuro) (MANSÍLLA, 2005, p. XXIII).

Nesse passo, os sistemas organizacionais são encarregados de oferecer soluções aos mais diversos problemas aos quais a sociedade é submetida (MANSíLLA, 2005, p. 161). Essa característica ressalta o aspecto teleológico que as organizações assumem, pois, ao passo em que o direito existe meramente com base em comunicações binariamente identificáveis, sua principal organização - o Poder Judiciário - possui uma paradoxal

Brasileiro: "Quando a lei for omissa, o juiz decidirá o caso de acordo com a analogia, os costumes e os princípios gerais de direito", ou, ainda, no artigo 126 do Código de Processo Civil Pátrio: "O juiz não se exime de sentenciar ou despachar alegando lacuna ou obscuridade da lei. No julgamento da lide caber-lhe-á aplicar as normas legais; não as havendo, recorrerá à analogia, aos costumes e aos princípios gerais de direito". 
finalidade: por um lado, decidir sobre comunicações que se identificam com o código direito/não-direito, por outro, atribuir o próprio sentido binário jurídico à essas mesmas comunicações, razão pela qual os tribunais assumem papel de vital importância na (re)produção do sentido específico do direito.

\section{A PRODUÇÃO DO SENTIDO JURÍDICO EM UMA REALIDADE POLICONTEXTURAL}

Os tribunais surgem como um elemento produzido pela própria racionalidade do sistema do direito. Enquanto organização, o Poder Judiciário ocupa-se com a observação, descrição e, principalmente, a decisão sobre comunicações que obedecem a lógica binária jurídica. Entretanto, as decisões dos tribunais atuam paradoxalmente. Como afirmado, tais organizações ocupam-se com comunicações jurídicas, porém, ao mesmo tempo, essas comunicações são igualmente constituídas pela própria operacionalidade jurídico-organizacional.

O problema relacionado à produção do sentido jurídico em uma realidade policontextural surge precisamente quando se passa a reconhecer uma realidade multifacetada e interdiscursiva. A racionalidade jurídica tradicional não é capaz de operacionalizar esse tipo de problema. Enquanto a dogmática jurídica permanece agrilhoada ao passado, o direito contemporâneo reclama decisões que levem em conta a complexidade, pluralidade, paradoxos e riscos que caracterizam a sociedade moderna.

Rocha (2009, p. 37) afirma que uma alternativa para a análise do fenômeno jurídico é a observação do direito como sistema autopoiético. Nesse passo, o autor realiza a distinção entre sistemas autopoiético e atores sociais. Enquanto os primeiros são constituídos por comunicações e ocupam-se com a sua própria manutenção autopoiética, os segundos caracterizam-se como interações e organizações. Na esteira luhmanniana, Rocha segue afirmando que o Poder Judiciário ocupa o centro do sistema de comunicação jurídica, possuindo como função a tomada de decisões diante de situações de indeterminação e incerteza. Essa perspectiva é evidenciada, ainda, quando sintetiza a proposta construtivista aduzindo que

os juristas observam o mundo a partir do sistema do direito, e ele depende, para a sua efetividade, do Poder Judiciário como organização. Para um mínimo de efetividade, é necessário ter-se a clareza desse fato. graças às operações das organizações, far-se-á a construção de um mundo conforme o Direito. Ou seja, a ideia de autopoiese diz o seguinte: o sistema do Direito tem que autorreproduzir uma organização, para, a partir daí, ela definir seus próprios problemas, seus próprios limites e construir a sua verdade (que é sempre uma construção). (2009, p. 37)

Essa autorreprodução do direito é verificada justamente pela existência de tribunais. Os tribunais possibilitam a continuidade das comunicações jurídicas a partir de sua capacidade em delimitar seus próprios problemas, limites, qualidade dos membros e formas do exercício do Poder. A questão do poder, aliás, é um aspecto interessante a ser salientado, principalmente no que diz respeito àquelas posições tendentes a observar a 
decisão judicial como livre de qualquer amarra. A teoria dos sistemas sociais não se ocupa com a busca uma única resposta correta, como quer Dworkin (2005, p. 239), todavia, possibilita a observação de que tal resposta é dada pelo próprio comportamento organizacional.

Quando se assume uma teoria que observa a complexidade, a diferença e que reconhece o direito como um sistema comunicativo capaz de delimitar seus próprios pressupostos operativos, os limites da decisão judicial passam a ser dados pela própria organização. Em outras palavras, partindo-se da ideia de organização, existem fronteiras decisoriamente delimitadas, dos quais seus membros organização (no caso do Poder Judiciário: juízes, servidores, assessores, escrivães, etc) não podem prescindir. Ou seja, a resposta correta perseguida por Dworkin e, de certo modo, igualmente por Habermas (2003, p. 323) -, não encontra sua viabilidade na legislação, na Constituição ou em princípios pretensamente fundantes do sistema jurídico, mas sim na própria forma pela qual a organização judiciária responde a determinado problema.

No caso do Poder Judiciário, as regras organizacionais recaem, primeiramente sobre os juízes, eis que membros da organização encarregados de processos de tomadas de decisão. Dos juízes, esperam-se decisões que se mantenham dentro daquilo considerado juridicamente aceitável. Qualquer decisão discrepante com a normalidade delimitada pela organização é passível de reforma (LUHMANN, 2005, p. 391-392). Nesse passo, a decisão judicial sempre será realizada por tribunais, sendo que a lógica jurídica passa a ser continuamente transformada justamente pelo sentido de direito atribuído pela decisão judicial e assimilado pelo sistema.

O sistema jurídico obriga-se a delimitar suas autodescrições desde uma perspectiva própria. Nesse contexto, o direito é constrangido a amoldar sua complexidade internamente estruturada à complexidade externa - desordenada ou ordenada mediante racionalidades diversas. Justamente a partir dessa instabilidade, o direito passa a orientar-se desde a produção de uma normatividade contrafática, reagindo às perturbações exteriores mediante estratégias como a ideia de positivação da validade jurídica, o arrolamento de valores que assumem a forma de princípios, e assim por diante.

Quando Carvalho (2009, p.32) observa a formação do sentido jurídico do meio ambiente, explica que a instrumentalização dos processos de tomada de decisão jurídica, principalmente em relação aos novos direitos, decorre da formação de comunicações produzidas e reproduzidas sob a especificidade do código jurídico. Logo, a comunicação caracteriza-se como o elemento social capaz de proporcionar essa autorreprodução da sociedade e de seus sistemas parciais, sendo que a contínua produção da diferença possibilita múltiplas descrições da realidade e fornece os elementos necessários para a construção de uma imagem jurídica na policontexturalidade.

A questão da policontexturalidade, contudo, permanece latente. É interessante o questionamento realizado por Teubner, quando pergunta "se o direito e os outros discursos sociais fecham suas fronteiras com a utilização do código de comunicação binário, como, ainda assim, pode haver interdiscursividade?” (2005, p. 90) A 
partir dessa pergunta pode-se traçar determinadas observações:

1. O direito contemporâneo opera sob condições de clausura operacional, não sendo delimitado por outras racionalidades sociais;

2. Essa mesma operacionalidade jurídica proporciona que o sistema se autorreproduza no sentido de constituição de organizações capazes de decidir em níveis dotados de extrema complexidade. Para o direito, sua principal organização é o Poder Judiciário;

3. O Poder Judiciário passa a atrair a competência para as decisões dos casos de relevância jurídica, passando a decidir desde o centro do sistema jurídico;

4. Ao mesmo tempo em que a centralidade do direito é ocupada pelos tribunais, na periferia do sistema encontram-se a legislação e uma incontável quantidade de manifestações igualmente jurídicas, isto é, de comunicações que também orientam-se mediante o código direito/não-direito;

5. A policontexturalidade jurídica, então, passa a caracterizar-se como um problema a ser resolvido pelos tribunais, eis que estes precisam decidir em um contexto de pluralidade e incerteza. A questão que se coloca, então, passa a ser a seguinte: como equalizar decisoriamente racionalidades jurídicas distintas e, por vezes, conflitantes?

O questionamento de Teubner, portanto, guarda relevância com essa pergunta, afinal, o mero conceito de acoplamento estrutural não é suficientemente complexo para oferecer respostas a tal problema. Neves (2009, p. 34-35 e 184) oferece uma interessante alternativa, quando, a partir do reconhecimento da multicentralidade da sociedade, vale-se da possibilidade de uma realidade que permita o diálogo entre discursos jurídicos autônomos. Teubner (2005, p. 98) igualmente reconhece que o pluralismo jurídico (policontexturalidade jurídica) permite uma abertura do direito em relação à sociedade.

Essa possibilidade de diálogo parte do reconhecimento de que a realidade funda-se mediante o estabelecimento de hierarquias entrelaçadas de níveis múltiplos, no sentido atribuído por Hofstadter (2001, p. 760-762). Dito de outro modo, os tribunais devem observar a pluralidade de possibilidades que os cercam, buscando estabelecer o contínuo diálogo entre discursos jurídicos pretensamente oficiais e racionalidades jurídicas que emanam espontaneamente da sociedade.

A formação de um sentido jurídico na policontexturalidade, portanto, não decorre de critérios imutáveis dogmaticamente considerados, mas sim de decisões comprometidas com o desenvolvimento da organização e, via de consequência, do próprio direito, reconhecendo-se igualmente a multiplicidade de racionalidades que se localizam na periferia do sistema do direito.

Nesse passo, uma teoria jurídica com pretensão de observar a realidade plural que, inegavelmente, caracteriza a sociedade contemporânea, deve partir do reconhecimento da policontexturalidade e da possibilidade 
de contínuos diálogos entre racionalidades conflitantes. A partir disso, então, pode-se falar na formação de um sentido jurídico da policontexturalidade, sendo tal atribuição de sentido tarefa do Poder Judiciário enquanto organização central do sistema do direito.

Por fim, a efetividade do direito passa a depender justamente da observação dessa realidade policontextural, havendo a premente necessidade de debate contemporâneo ultrapassar discussões relacionadas à validade do direito para, com isso, reconhecer no diálogo e na interdiscursividade as alternativas possíveis para um sistema jurídico que insiste em observar um futuro arriscado e plural mediante arranjos simplificados e dogmáticos.

\section{CONSIDERAÇÕES FINAIS}

Ao descrever-se como complexa, a sociedade contemporânea assume a existência de múltiplas possibilidades comunicativas. Isso implica na evidente necessidade de mecanismos capazes de decidir em níveis hipercomplexos, razão pela qual se afirma a existência de sistemas funcionais cuja racionalidade específica traduz a complexidade ambiental desordenada em complexidade funcional sistemicamente organizada. Em outras palavras, quanto maior a capacidade de controle do próprio sistema, maior sua capacidade de controlar seu entorno.

Nesse mesmo contexto, a sociedade possibilita sua autoobservação como policontextural. A policontexturalidade, em um primeiro momento, reflete as múltiplas existências sistêmicas concorrentes, demonstrando, sob uma observação construtivista, que a verdade é sempre uma construção do observador e que, em razão dessa particularidade, coexistem realidades diversas e conflitantes.

O grande salto teórico que o conceito de policontexturalidade proporciona, entretanto, diz respeito à sua reconstrução no âmbito jurídico. Dito de outro modo, Teubner aponta para o reconhecimento de que, no próprio âmbito do sistema jurídico, os discursos igualmente fragmentam-se, deslocando da figura do Estado o monopólio da produção da normatividade e identificando a produção normativa como decorrente de uma série de atores descentralizados.

Dessa maneira, a policontexturalidade passa a ser observada juridicamente. Não é apenas a multiplicidade de discursos racionais que caracteriza essa pluralidade de vivências, mas igualmente a capacidade de determinadas racionalidades sociais em assumir a codificação própria do direito. Em outras palavras, na sociedade contemporânea desenvolvem-se complexas redes comunicativas, possibilitando a emergência de centros descentralizados de poder.

A ideia de organização é palavra chave para tal problema. Ao mesmo tempo em que o Poder Judiciário se apresenta na forma de uma organização própria do sistema jurídico, outros sistemas organizacionais tornam-se 
capazes de literalmente produzir normas jurídicas, deslocando o problema da discussão sobre validade normativa para a questão da efetividade decisória.

A efetividade regulativa, por sua vez, passa a depender de uma evidente necessidade de coevolução entre racionalidades jurídicas diversas e, por vezes, contraditórias. Ao reconstruir a realidade mediante sua lógica específica, o sistema jurídico - por meio da atuação dos tribunais - torna-se capaz de realocar o problema da pluralidade discursiva, passando a decidir justamente com base nessa multiplicidade de razões possíveis. A efetividade da decisão judicial depende, em enorme grau, do reconhecimento da policontexturalidade bem como das evidentes limitações impostas pelo código do direito.

Dito de outro modo, a solução para o problema da efetividade e do reconhecimento da pluralidade jurídica que caracterizam o direito contemporâneo depende de uma reviravolta na própria abordagem organizacional do problema. O diálogo entre discursos concorrentes é uma realidade possível, todavia, dependente de um necessário rompimento para com a vetusta forma pela qual os tribunais observam a realidade.

\title{
POLICONTEXTURAL SOCIETY, LEGAL SENSE AND EFFECTIVENESS
}

\begin{abstract}
Contemporary society is permanently constructed by a paradoxical attempt to reduce complexity. Such operations are built within the organizational systems that, because of their ability to make decisions, allow complexity to be worked out. One of this organizations is the Judiciary. In this context, the system of law is constituted from a set of decisions operations that, necessarily, coexist with other systemic rationalities, producing a crisis (internal and external) of the effectiveness of judicial decisions. Therefore, different observations are necessary in order to construct alternatives for such a problem.
\end{abstract}

Keywords: Law; Effectiveness; Judicial Power; Polycontexturality; Theory of Systems.

\section{REFERENCIAS}

CARVALHO, Délton Winter de. A formação sistêmica do sentido jurídico do meio ambiente. São Leopoldo: Revista de Estudos Constitucionais, Hermenêutica e Teoria do Direito (RECHTD). n. 1. v. 1. jan/jun. 2009. p. 28-36.

Dano ambiental futuro: a responsabilização civil pelo risco ambiental. Rio de Janeiro: Forense Universitária, 2008.

CORSI, Giancarlo. Sociologia da constituição. Revista da Faculdade de Direito da Universidade Federal da Minas Gerais. Belo Horizonte: UFMG, n. 39, jan./jun. 2001.p. 169-189.

DWORKIN, Ronald. Uma questão de princípio. São Paulo: Martins Fontes, 2005. 
HABERMAS, Jürgen. Direito e democracia: entre facticidade e validade. v. I. 2. ed. Rio de Janeiro: Tempo Brasileiro, 2003.

HOFSTADTER, Douglas R. Gödel, Escher, Bach: um entrelaçamento de gênios brilhantes. Brasília: UNB, 2001.

LUHMANN, Niklas. Ecological communication. Chicago: The University of Chicago Press, 1989.

¿Cómo se pueden observar estructuras latentes? In: WATZLAWICK, Paul; KRIEG, Peter. El ojo del observador: contribuciones al constructivismo. Barcelona: Gedisa, 1998.

A estabilidade instável. In: SILVA, Juremir Machado da. O pensamento do fim de século. Porto Alegre:

L\&PM, 1993. p. 218-219. Entrevista concedida a Juremir Machado da Silva, realizada em Porto Alegre, em setembro de 1990.

A improbabilidade da comunicação. 3. ed. Lisboa: Vega, 2001.

168.

A posição dos tribunais no sistema jurídico. Ajuris, Porto Alegre, Ajuris, n. 49, ano XVII, jul., 1990. p. 149-

A terceira questão: o uso criativo dos paradoxos no Direito e na história do Direito. Estudos jurídicos, São Leopoldo, n. 32, jan./jun., 2006. p. 45-52.

El derecho de la sociedad. Ciudad de México: Universidad Iberoamericana/Herder Editorial, 2005.

La sociedad de la sociedad. Ciudad de México: Universidad Iberoamericana/Herder Editorial, 2007.

O conceito de sociedade In: NEVES, Clarissa Eckert Baeta; SAMIOS, Eva Machado Barbosa (Org.).

Niklas Luhmann: A nova teoria dos sistemas. Porto Alegre: Editora da Universidade/Goethe-Institut, 1997.

O enfoque sociológico da teoria e prática do direito. Seqüência, Florianópolis: Fundação Boiteux, n. 28, jun., 1994.p. 15-29.

Organización y decisión. Autopoiesis, acción y entendimiento comunicativo. Barcelona/México/Santiago de Chile: Anthropos Editorial/Universidad Iberoamericana/Pontifícia Universidad Católica de Chile, 2005.

Sociologia do direito. Rio de Janeiro: Tempo Brasileiro, 1983.v. I.

LUHMANN, Niklas; DE GIORGI, Raffaele. Teoría de la Sociedad. Guadalajara, México: Universidad de Guadalajara/ Universidad Iberoamericana/Iteso, 1993.

MAGALHÃES, Juliana Neuenschwander. O uso criativo dos paradoxos do direito. In: ROCHA, Leonel Severo. Paradoxos da auto-observação: percursos da teoria jurídica contemporânea. Curitiba: JM, 1997. p. 243-277.

MANSILLA, Darío Rodríguez. Nota a la versión en español. In. LUHMANN, Niklas. Organización y decisión. autopoiesis, acción y entendimento comunicativo. Barcelona/México/Santiago de Chile: Anthropos Editorial/Universidad Iberoamericana/Pontifícia Universidad Católica de Chile, 2005, p. VII-XXXIII.

Organizaciones para la modernización. Ciudad de Mexico: Universidad Iberoamericana. 2004.

MARCH, James Gardner; SIMON, Herbert Alexander. Teoria das organizações. 2. ed. Rio de Janeiro: FGV, 1972.

NAFARRATE, Javier Torres. Nota a la versión en español. In: LUHMANN, Niklas. Sociología del riesgo. México: Triana Editores, 1998.

NEVES, Clarissa Eckert Baeta. Niklas Luhmann e sua obra. In: NEVES, Clarissa Eckert Baeta; SAMIOS, Eva Machado Barbosa (Org.). Niklas Luhmann: A nova teoria dos sistemas. Porto Alegre: Editora da Universidade/Goethe-Institut, 1997.p. 9-17. 
NEVES, Marcelo. Transconstitucionalismo. São Paulo: Martins Fontes, 2009.

ROCHA, Leonel Severo. Direito, complexidade e risco. Seqüência, Florianópolis: Fundação Boiteux, n. 28, jun., 1994.p. 1-14.

Observações sobre a observação luhmanniana. In ROCHA, Leonel Severo, KING, Michael; SCHWARTZ, Germano. A verdade sobre a autopoiese no direito. Porto Alegre: Livraria do Advogado, 2009. p. $11-40$.

Observações sobre autopoiese, normativismo e pluralismo jurídico. In: STRECK, Lenio Luiz; MORAIS, José Luis Bolzan de. Constituição, sistemas sociais e hermenêutica. n. 4. São Leopoldo: Unisinos, 2008. p. 169170.

TEUBNER, Gunther. As duas faces de Janus: pluralismo jurídico na sociedade pós-moderna. In: TEUBNER, Gunther. Direito, sistema e policontexturalidade. Piracicaba: Unimep, 2005. p. 79-104.

Global Bukowina: legal pluralism in the world society. In: TEUBNER, Gunther. (Ed.). Global Law Without a State. Aldershot: Dartmouth, 1997.

O direito como sistema autopoiético. Lisboa: Fundação Calouste Gulbenkian, 1989.

Trabalho enviado em 07 de agosto de 2017.

Aceito em 09 de novembro de 2017. 